\title{
Improved description of the ocean mesoscale variability by combining four satellite altimeters
}

\author{
Ananda Pascual $^{1}$, Yannice Faugère ${ }^{2}$, Gilles Larnicol ${ }^{2}$, Pierre-Yves Le Traon ${ }^{3^{*}}$ \\ ${ }^{1}$ Institut Mediterrani d'Estudis Avançats, Consejo Superior de Investigaciones Científicas/Universidad de las Islas \\ Baleares, Mallorca, Spain \\ ${ }^{2}$ Space Oceanography Division, CLS, Toulouse, France \\ ${ }^{3}$ Institut Francais de Recherche pour l'Exploitation de la Mer (IFREMER), Brest, France \\ *: Corresponding author : Pierre.Yves.Le.Traon@ifremer.fr
}

\begin{abstract}
Data from four satellite altimeters are combined with the aim of improving the representation of the mesoscale variability in the Global Ocean. All missions [Jason-1, ERS-2/ENVISAT, Topex/Poseidon interleaved with Jason-1 and Geosat Follow-On] are cross-calibrated previously to produce weekly gridded maps. In areas of intense variability, the rms differences between a classical configuration of two altimeters and the scenario merging four missions can reach $10 \mathrm{~cm}$ and 400 $\mathrm{cm} 2 / \mathrm{s} 2$ in SLA and EKE, respectively, which represents an important percentage of the signal variance. A comparison with surface drifters shows that the four altimeter scenario improves the recovery of mesoscale structures that were not properly sampled with Jason-1 + ERS-2/ENVISAT. Finally, the consistency between altimetric and tide gauge data is improved by about $25 \%$ when coastal sea level is estimated with 4 satellites compared to the results obtained with 2 altimeters.
\end{abstract}

Keywords: Global ocean, Mesoscale variability, Satellite altimeters 


\section{Introduction}

The mesoscale variability is the dominant signal in the ocean circulation. Eddies, vortices, fronts, jets, meanders, rings and filaments can be observed almost everywhere. Thus, resolving the mesoscale variability is crucial to correctly understand the dynamics of the ocean circulation and to estimate the associated heat transport, even at climatic scales (Wunsch, 1999). Satellite altimetry has provided a unique contribution to the global observation of eddy variability (see Le Traon and Morrow, 2001). In particular, it has been shown that the combination of two altimetric missions (Topex/Poseidon (T/P) and ERS-1/2 in the past, and Jason-1 and T/P interlaced tandem mission more recently) gives an improved estimation of the mesoscale surface ocean circulation compared to the results derived from only one altimeter (Ducet et al., 2000; Fu et al, 2003; Le Traon and Dibarboure, 2004). However, theoretical analyses (e.g. Le Traon and Dibarboure, 2002; Leeuwenburgh and Stammer, 2002; Chelton and Schlax, 2003) have explored the capabilities of different altimeter scenarios and have concluded that two satellite altimeters are still far from an optimal recovery of the mesoscale variability.

Fortunately, four satellite altimeters [Jason-1, ENVISAT, Geosat Follow-On (GFO) and T/P interlaced] are presently flying simultaneously, providing accurate complementary sea surface height measurements. Jason-1 and ENVISAT were launched as follow-on to the T/P and ERS-2 missions, respectively. Since September 2002, T/P was manoeuvred into an interleaved orbit with Jason-1, offering a significantly improved sampling for the study of eddy-scale variability. And finally, GFO is also producing altimeter data along Geosat ground tracks. As stated by Fu et al. (2003), the potential benefits of combining data from the 
four missions are envisaged to be very high for the estimation of high-resolution ocean surface topography.

The objective of this paper is to demonstrate the capabilities of improving the estimation of the mesoscale surface circulation in the Global Ocean by merging data of the above mentioned four altimeter missions. First, we present the data set and the method used to combine the different satellite data sets and to produce gridded maps. Next, we show the variability (both in sea level and Eddy Kinetic Energy) recovered by the four altimeters, as well as, the differences with respect to the signal captured with only 2 altimeters. In the last two sections we carry out a comparison with tide gauge and drifter data.

\section{Altimetric Data Processing}

Eleven months of Jason-1, ERS-2/ENVISAT, Topex/Poseidon interleaved (T/P) and Geosat Follow-On (GFO) delayed time data are used for this study. The data span from the beginning of the T/P interleaved mission (beginning of October 2002) to the end of August 2003. ERS-2 is replaced by ENVISAT by mid June 2003. All datasets are submitted to the usual geophysical corrections, i.e. the same used for the delayed time products delivered by AVISO, http://www.aviso.oceanobs.com (see Le Traon et al., 2003 for specific corrections of GFO).

Merging multisatellite altimeter missions requires homogeneous and cross-calibrated sea surface height (SSH) data sets, which are obtained by performing a global crossover adjustment of the ERS-2/ENVISAT, GFO and Jason-1 orbits using T/P SSH measurements as a reference (Le Traon and Ogor, 1998). To extract sea level anomalies (SLA), a specific mean profile is removed from the individual SSH measurements. For Jason-1 and ERS2/ENVISAT we use a mean profile calculated over a 7-year period (1993-1999). For T/P 
interleaved and GFO, a specific processing is applied in order to get mean profiles consistent with Jason-1 and ERS-2/ENVISAT mean profiles (see Le Traon et al., 2003 and Le Traon and Dibarboure, 2004).

The mapping method to produce gridded fields of SLA from along-track data is described in Le Traon et al (2003). Maps are calculated every week on a $1 / 3^{\circ}$ x $1 / 3^{\circ}$ Mercator grid (i.e., with the same resolution in latitude and longitude, which is approximately equal to 33 $\mathrm{km}$ times the cosine of latitude). The maps obtained combining four missions will be compared with the reference maps provided by AVISO that merge only two altimeters (Brachet et al, 2004).

\section{Sea Level and EKE variability}

The sea level variability detected by the combination of four altimeters is shown in Figure 1 (left top panel). The areas of intense mesoscale variability (e. g. the Antartic Circumpolar Current flowing continuously around the unbounded Southern Ocean and the major western boundary currents: Gulf Stream, Kuroshio, and Brazil-Malvinas Confluence Region) are clearly identified and are characterized by rms higher than $20 \mathrm{~cm}$. Other areas like the equatorial band and the Mediterranean sea have a more moderate variability (about 10-15 $\mathrm{cm})$. To assess the benefits of the 4 missions we compute SLA rms differences between the Jason-1 + ERS/ENVISAT + T/P interlaced + GFO configuration and the reference Jason-1 + ERS/ENVISAT scenario (Figure 1 right top panel). At low latitudes (between $20^{\circ} \mathrm{S}-20^{\circ} \mathrm{N}$ ), where the size of typical structures is quite large, the impact of the two additional altimeters is almost negligible. On the contrary, in areas of intense mesoscale variability located at mid and high latitudes, the rms differences between the 2 and the 4 altimeter configuration are in between 5 and $10 \mathrm{~cm}$, which represent an important percentage of the signal variability. 
An interesting variable to characterize the mesoscale is the Eddy Kinetic Energy (EKE), which is a measure of the degree of variability and may identify regions with highly variable phenomena such as eddies, current meanders, fronts or filaments. From SLA gridded maps it is possible to compute EKE (per unit of mass) by assuming a geostrophic balance (see Ducet et al, 2000 for details). As expected, the maximum levels of EKE concentrate in the vicinity of major currents systems (Figure 1, right bottom panel). Rms differences between EKE derived from the merging of 2 and 4 altimeters are also shown in Figure 1 (right bottom panel). At mid and high latitudes, where previous authors (Ducet et al., 2000; Le Traon and Dibarboure, 2002 and Brachet et al., 2004) have already found a clear underestimation of EKE due to the high frequency and high wavenumber that can not be mapped by the combination of two altimeters, the addition of T/P interlaced and GFO has an important effect. The rms differences can reach values higher than $400 \mathrm{~cm}^{2} / \mathrm{s}^{2}$. In fact, the merging of four altimeters contributes to a better continuity of all the structures. In the Mediterranean Sea, for instance, , where Pascual et al (2005) have performed a first test combining the data of 4 altimeters, the reference configuration of Jason- $1+$ ERS-2, failed to reproduce some intense signals, generally associated with mesoscale activity. On the contrary, when T/P interleaved and GFO are added to the reference configuration, these features are well recovered and the EKE does not show significant discontinuities due to sampling effects.

\section{Comparison with surface drifter data}

In this section, velocities derived from altimetry are compared with those obtained from surface drifter data. Absolute currents are reconstructed by adding to the geostrophic anomaly velocities, the mean currents obtained from the mean dynamic topography of Rio and Hernandez (2004), plus an Ekman component (Rio and Hernandez, 2003). The wind data 
come from CERSAT products (ftp://ftp.ifremer.fr/ifremer/cersat/products/gridded/mwfquikscat/ ). Absolute currents fields are then interpolated onto the position and time of the drifter data. The lagrangian data set used here is provided by the Atlantic Oceanographic and Meteorological Laboratory (AOML, http://www.aoml.noaa.gov/phod/dac/) and contains 673,000 measures of floats drogued at $15 \mathrm{~m}$. Inertial oscillations and other high-frequency motions were filtered by applying a 3-day low pass filter.

The mean square differences between altimetric (combining 4 altimeters) and drifter velocities, present a quite homogeneous pattern (Figure 2). In average, in energetic zones (rms higher than $20 \mathrm{~cm} / \mathrm{s}$ ), the misfits for the $\mathrm{U}$ and $\mathrm{V}$ components are as low as $24.3 \%$ and $28.4 \%$ of the drifter variance, respectively, which implies a correction, from two to four missions, of about $9 \%$ and $15 \%$, respectively. Note that the figures given above also contain the errors on drifter data, including both interpolation errors and residual signals due to the direct effect of wind-forcing on the surface float and non linear wave phenomena.

Figure 3 presents an example of a buoy that was entrained in a cyclonic eddy in the Gulf Stream during about two weeks (14-28 May 2003). The trajectory followed by the drifter is in good agreement with the velocity vectors and the map of absolute dynamic topography of 21 May 2003 obtained from the combination of 4 satellites, which also presents a cyclonic eddy in the same location and with very similar shape and size. Conversely, the reference configuration merging only Jason+ERS-2 failed to correctly reproduce this structure.

\section{Comparison with tide gauge data}

Coastal altimeter observations are often of low accuracy (e.g. Vignudelli et al., 2005). However, some gain is expected from the combination of several altimeter missions. We use 
86 tide gauge (TG) stations from GLOSS/CLIVAR near-real time data (University of Hawai Sea Level Center: http://ilikai.soest.hawaii.edu/uhslc/). Only complete time series without gaps are selected. The processing of the tide gauge data consisted of filtering tides and the application of the inverse barometer correction. The altimetric maps are interpolated onto the position of the TG stations. Both time series are filtered out with a 20 days low pass filter in order to remove the high frequencies that can not be resolved by altimetric data.

Figure 4 shows the consistency between TG data and altimetry from the combination of 4 altimeters. Mean square differences (in terms of percentage of the TG variance) are lower than $20 \%$ in the islands, whereas for continental coastal stations the misfit is in between 20$40 \%$. The largest errors, which reach $100 \%$, are found in areas where the tidal model used for the altimetric data is not accurate enough (GOT-99). This is expected to be improved in the near future with new tidal models (GOT-00, FES-2004). Again, it is also important to note that tide gauges are not error free. The merging of the 4 missions has a significant impact, since the error variance averaged over all the TG stations is $35.3 \%$, while for the Jason- $1+$ ERS-2/ENVISAT scenario, the error is $46.7 \%$, which represents a relative reduction of about 25\%. Other improvements should come from a better estimation of the wind and pressure effects such as the application of the MOG2D, as it is performed in Vignudelli et al. (2005).

\section{Conclusions and perspectives}

We have successfully merged four altimeter missions [Jason-1, ERS-2/ENVISAT, Topex/Poseidon interleaved with Jason-1 and Geosat Follow-On] to produce improved global high resolution sea level anomaly maps. This new set of maps provides a better description of the mesoscale. In areas of intense variability, the rms differences between the classical configuration Jason-1 +ERS-2/ENVISAT and the merging of the four missions can reach 10 
$\mathrm{cm}$ and $400 \mathrm{~cm}^{2} / \mathrm{s}^{2}$ in SLA and EKE, respectively, which represents an important percentage of the signal variance. Absolute velocities have been computed by adding a mean geostrophic current and the Ekman component to the geostrophic anomaly velocities. These velocity fields have been compared with surface drifter data. Mean square differences (in terms of float variance) are quite homogeneous and smaller than 30\% for both zonal and meridional velocity components. The four altimeter scenario is able to reproduce some mesoscale features that are missing in the two mission configuration. Finally, a comparison with tide gauge data has shown that the merging of four altimeter missions has a significant impact in reducing the errors (by a factor of about 25\%) in the estimation of sea level in coastal areas. This represents a big challenge for satellite altimetry.

Furthermore, the impact of 4 altimeters is expected to be critical for operational systems running numerical models that assimilate real time altimetric data, mainly because there are less available data (i.e. only passed measurements are used). A preliminary comparison with surface buoys shows that, in real time, 4 altimeters would be needed to get the same scores as in delayed time with only 2 altimeters. Future studies should confirm these exploratory results by evaluating the impact of mapping sea level and velocities with real time data of 4 altimeter missions.

Unfortunately, the future of satellite altimetry is uncertain. At the moment, only one further altimeter mission (Jason-2) is planned and approved. There is an urgent requirement to fly a post ENVISAT altimeter mission but, as demonstrated in this paper, higher resolution will be ultimately needed. In the longer run, the concept of swath altimetry (Fu and Rodriguez, 2004) should also be explored. 


\section{ACKNOWLEDGEMENTS}

The study was partly funded through the EU Marine EnviRonment and Security for the European Area (MERSEA) - Integrated Project (Contract No. AIP3-CT-2003-502885).The altimeter products combining two missions were produced by SSALTO/DUACS as part of the Environment and Climate European Enact project (EVK2-CT2001-00117) and distributed by AVISO, with support from CNES. The authors thank Fabien Lefèvre and Eric Senant for the processing of tide gauge data. Ananda Pascual acknowledges a Marie Curie Host Industry Fellowship funded by the European Commission.

\section{REFERENCES}

Brachet, S., P. Y. Le Traon, and C. Le Provost (2004), Mesoscale variability from a highresolution model and from altimeter data in the North Atlantic Ocean, J. Geophys. Res., 109, C12025, doi: 10.1029/2004JC002360.

Chelton, D. B. and Schlax, M. G. (2003), The accuracies of smoothed sea surface height fields constructed from tandem satellite altimeter datasets, J. Atmos. Oceanic Technol., 20: 1276-1302.

Ducet, N., P.Y. Le Traon, and G. Reverdin (2000), Global high resolution mapping of ocean circulation from the combination of TOPEX/POSEIDON and ERS-1/2. J. Geophys. Res., 105, C8: 19477-19498.

Fu, L. -L., Stammer, D., Leben, B.B. and Chelton, D. B. (2003), Improved spatial resolution of ocean surface topography from the TOPEX/Poseidon - Jason-1 tandem altimeter mission, EOS, Vol 84, No. 26: 241, 247-248. 
Fu, L.-L., and R. Rodriguez (2004), High-resolution measurement of ocean surface topography by radar interferometry for oceanographic and geophysical applications, AGU Geophysical Monograph 150, IUGG Vol. 19: "State of the Planet: Frontiers and Challenges", R.S.J. Sparks and C.J. Hawkesworth, editors, 209-224.

Leeuwenburgh, O., and D. Stammer (2002), Uncertainties in altimetry-based velocity estimates. J. Geophys. Res., 107(C10), 3175, doi:10.1029/2001JC000937.

Le Traon, P.Y., and F. Ogor (1998), ERS-1/2 orbit improvement using TOPEX/POSEIDON: The 2 cm challenge, J. Geophys. Res., 103: 8045-8057.

Le Traon, P.-Y., and R. Morrow (2001), Ocean currents and eddies, in Satellite Altimetry and Earth Sciences, edited by L.-L. Fu and A. Cazenave, pp. 171-215, Academic, San Diego, California.

Le Traon, P.Y., and G. Dibarboure (2002), Velocity mapping capabilities of present and future altimeter missions: the role of high frequency signals, J. Atmos. Oceanic Technol., 19: 2077-2088.

Le Traon, P.Y., Y. Faugère, F. Hernandez, J. Dorandeu, F. Mertz, and M. Ablain (2003): Can we merge GEOSAT Follow-On with TOPEX/POSEIDON and ERS-2 for an improved description of the ocean circulation? J. Atmos. Oceanic Technol., 20: 889895.

Le Traon, P.Y., and G. Dibarboure (2004), An illustration of the unique contribution of the TOPEX/Poseidon - Jason-1 tandem mission to mesoscale variability studies. Marine Geodesy, 27: 3-13. 
Pascual, A. , M-I Pujol, G. Larnicol, P-Y Le Traon, M-H Rio (2005), Mesoscale Mapping Capabilities of Multisatellite Altimeter Missions: First Results with Real Data in the Mediterranean Sea, J. Mar. Sys., accepted.

Rio, M.-H. and F. Hernandez (2003), High-frequency response of wind-driven currents measured by drifting buoys and altimetry over the world ocean, J. Geophys. Res., 108: p. 3283, doi:10.1029/2002JC001655.

Rio, M.-H. and F. Hernandez (2004), A Mean Dynamic Topography computed over the world ocean from altimetry, in-situ measurements and a geoid model, J. Geophys. Res., 109: C12032, doi:10.1029/2003JC002226.

Vignudelli, S., P. Cipollini, L. Roblou, F. Lyard, G. P. Gasparini, G. Manzella, and M. Astraldi (2005), Improved satellite altimetry in coastal systems: Case study of the Corsica Channel (Mediterranean Sea), Geophys. Res. Lett., 32, L07608, doi: 10.1029/2005GL022602.

Wunsch, C., (1999), Where does ocean eddy heat fluxes mater?, J. Geophys. Res., 104(C6), 13,235-13,249. 


\section{FIGURES}

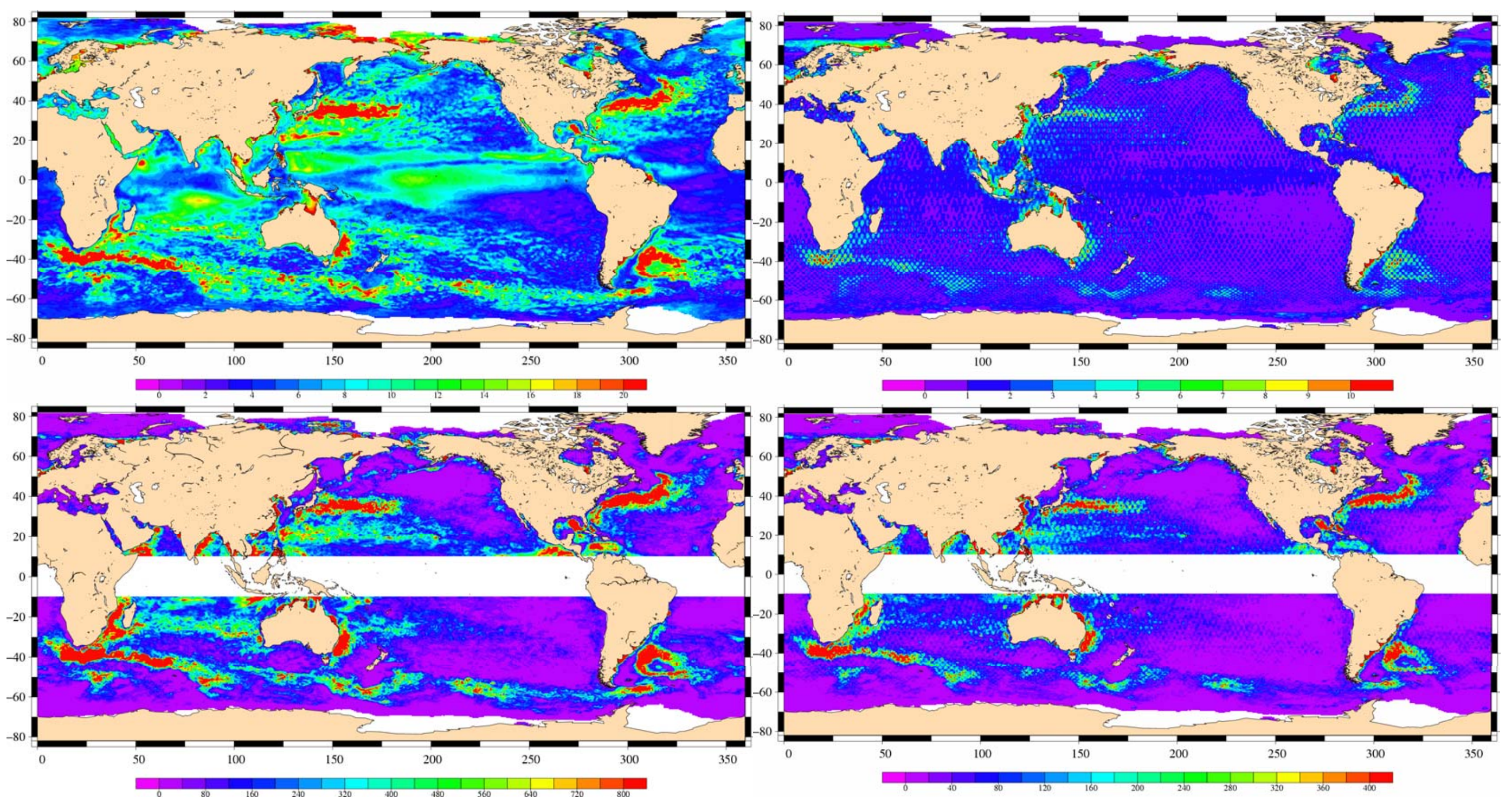

Figure 1 : Upper panels: on the left, rms of sea level anomaly (SLA) estimated with 4 altimetric missions (Jason-1 + T/Pinterlaced + ERS-2/ENVISAT + GFO). On the right, rms of SLA differences between 4 and 2 satellites. Units are cm. Lower panels: as for the upper panels but for eddy kinetic energy (EKE). Units are cm²/s². 

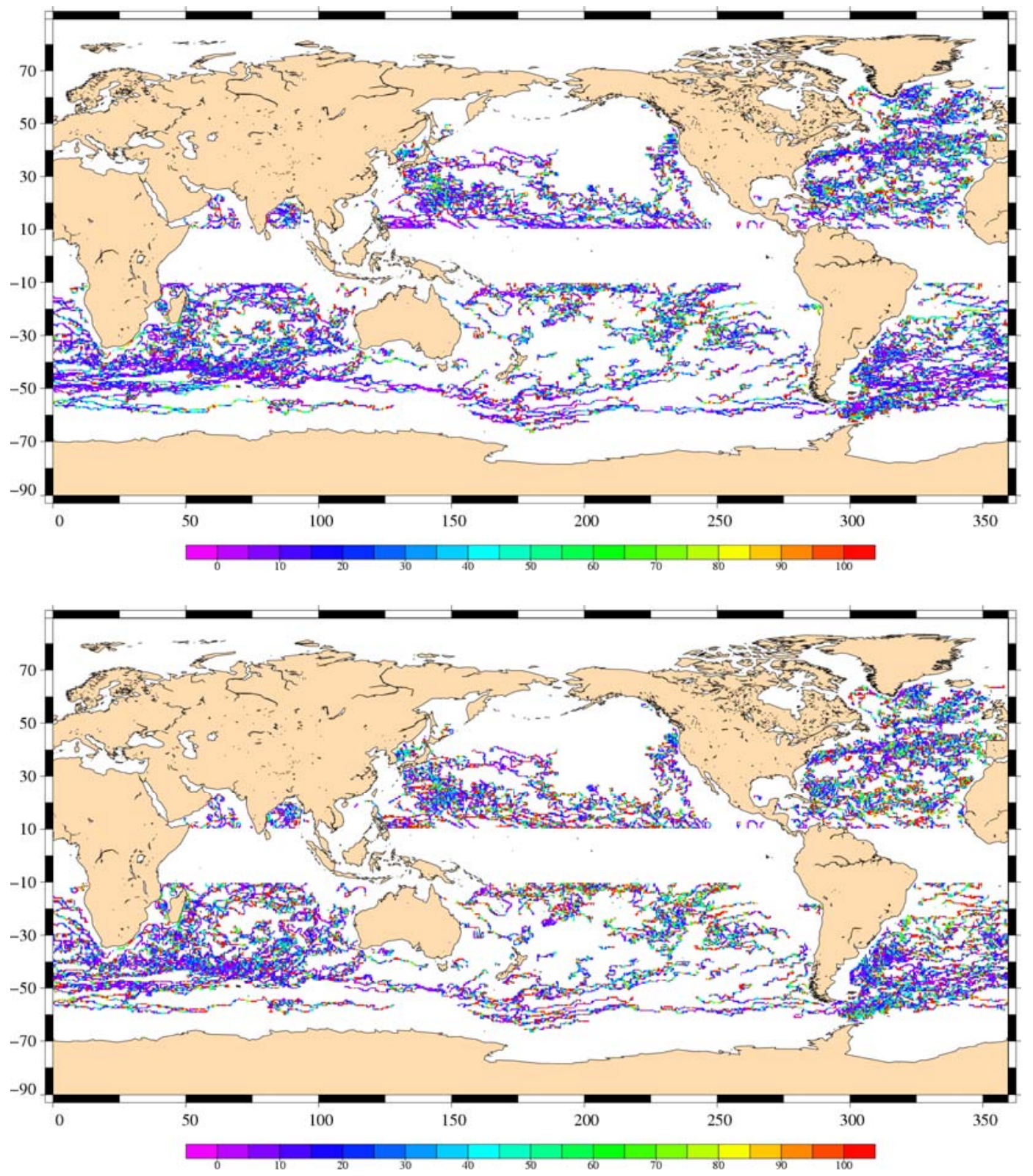

Figure 2 : Mean square differences between drifter and altimeter velocities. Top: Zonal (U) component. Bottom: Meridional (V) component. The altimetric speeds are derived from the combined Jason-1 + ERS-2/ENVISAT + T/Pinterlaced + GFO maps [including Ekman and mean currents]. The data are binned in square boxes of $0.5^{\circ} \times 0.5^{\circ}$. Units are $\%$ of drifter variance. 


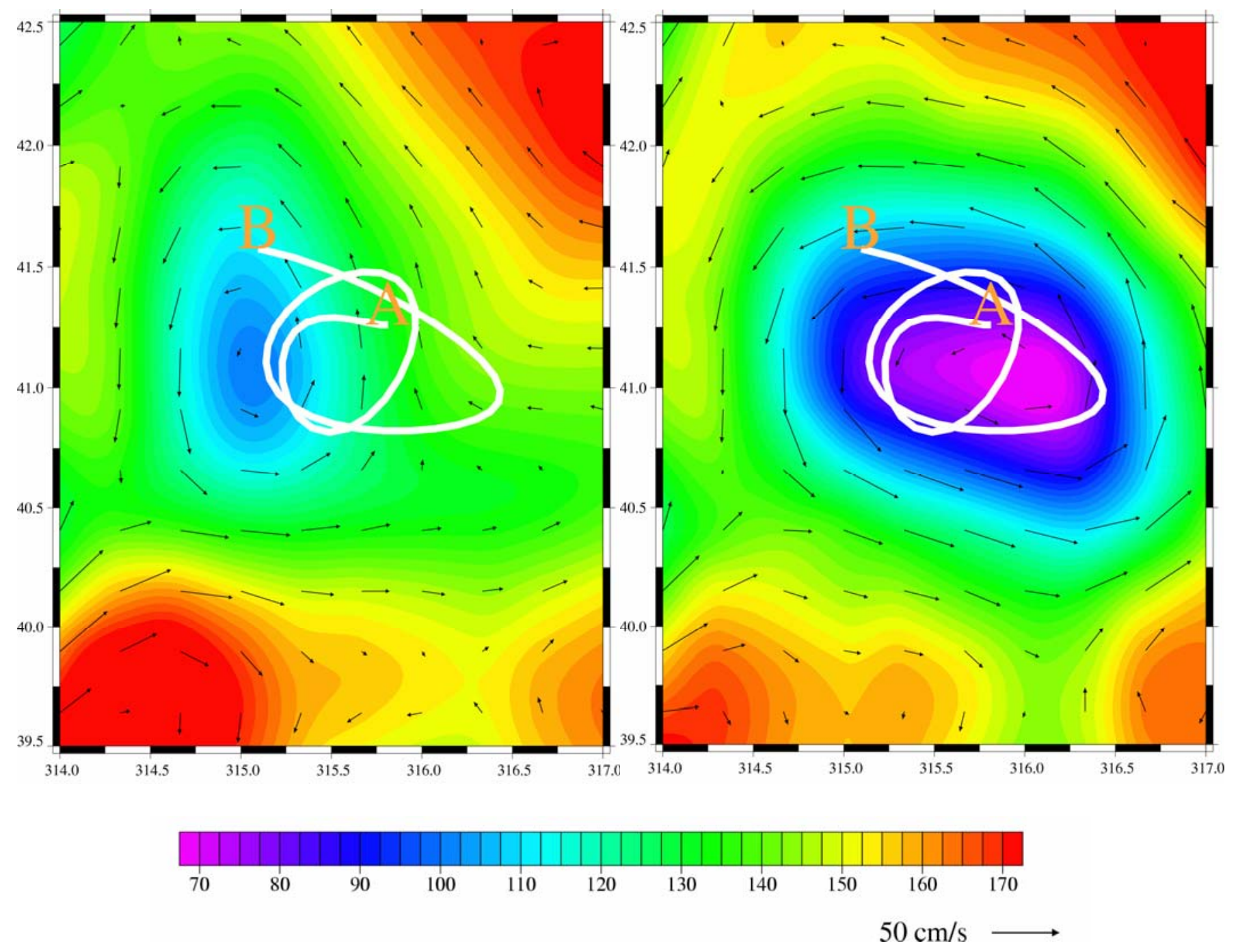

Figure 3: Comparison of altimetry and drifter data in a cyclonic eddy of the Gulf Stream.

The white line represents the trajectory followed by a surface float between 14 May 2003 (A) and 28 May 2003 (B). The vectors correspond to the absolute velocity field (geostrophy + Ekman) and the background color field is the SLA+MDT (in cm) on 21 May 2003 from the 2- (left) and 4- (right) satellite configurations. 


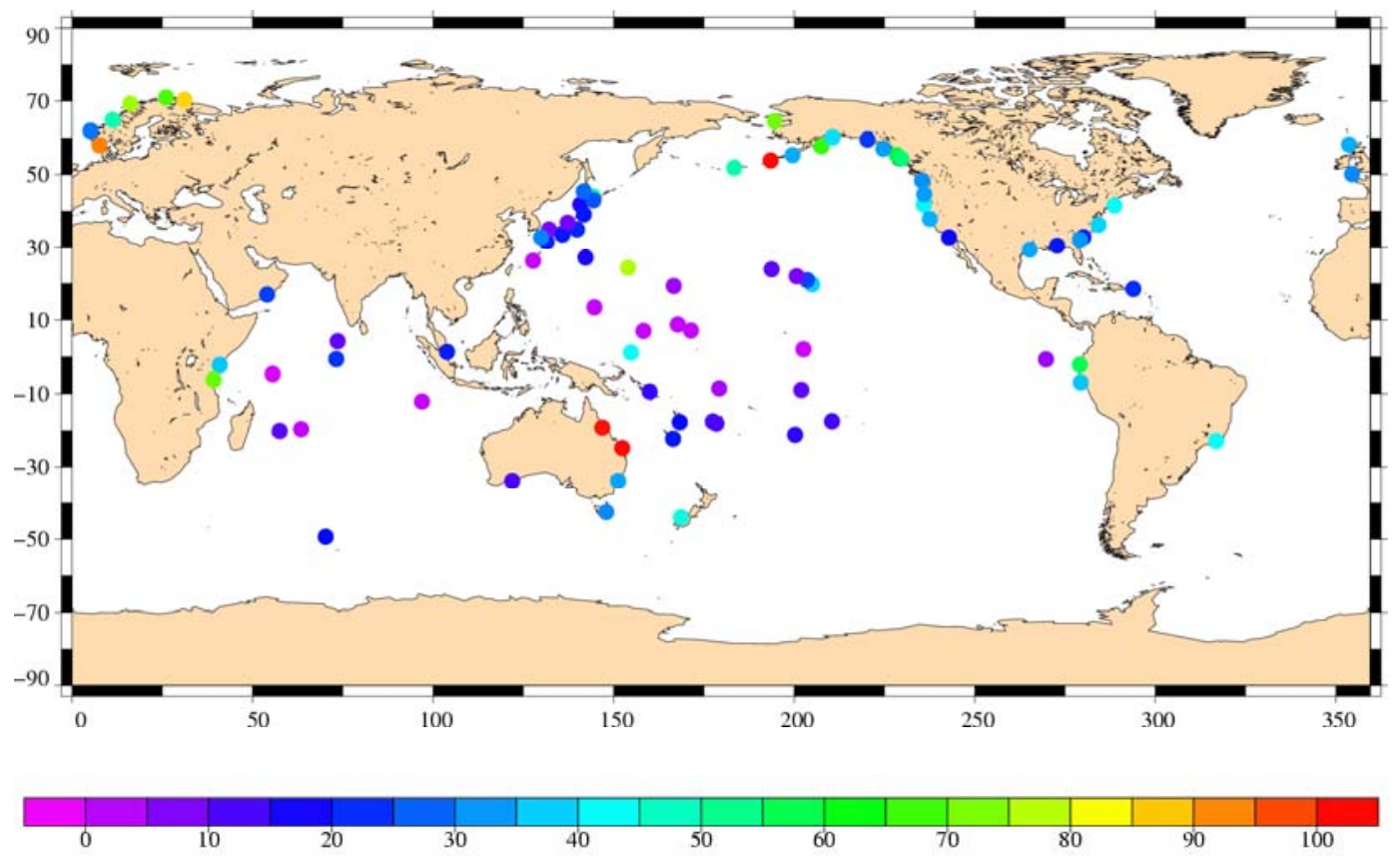

Figure 4 : Mean square differences between tide gauge and altimetry (from the 4-mission scenario) sea level. Units are \% of of tide gauge variance. 